\title{
Retroperitoneal extension of massive ulcerated testicular seminoma through the inguinal canal: A case report
}

\author{
Alessio Antonaci ${ }^{1}$, Daniela Fasanella ${ }^{1}$, Vikiela Galica ${ }^{2}$, Nicola Tinari ${ }^{3}$, Jamara Giampietro ${ }^{4}$, \\ Pietro Di Marino ${ }^{4}$, Andrea Delli Pizzi ${ }^{5}$, Raffaella Basilico ${ }^{5}$, Luigi Schips ${ }^{1}$, Michele Marchioni ${ }^{1}$ \\ ${ }^{1}$ Department of Medical, Oral and Biotechnological Sciences, G. d'Annunzio University of Chieti, Urology Unit, SS. Annunziata \\ Hospital, Chieti, Italy; \\ 2 Department of Biotechnological and Applied Clinical Sciences, University of L'Aquila "San Salvatore" Hospital, L'Aquila, Italy; \\ ${ }^{3}$ Department of Medical, Oral and Biotechnological Sciences and Center for Advance Studies and Technology (CAST), \\ G. D'Annunzio University of Chieti, Italy; \\ ${ }^{4}$ Clinical Oncology Unit, SS Annunziata Hospital, Chieti, Italy; \\ ${ }^{5}$ Department of Neuroscience, Imaging and Clinical Sciences, G. d'Annunzio University of Chieti, Chieti, Italy.
}

\begin{abstract}
Summary Introduction: Testicular cancers represent about $5 \%$ of all urological malignancies and $1-1.5 \%$ of all male neoplasms. Most of the testicular cancers are localized (68\%) at diagnosis. Bulky masses in the scrotum are rare. We present a rare case of bulky testicular cancer with retroperitoneal spread through the inguinal canal. Case report: A 44-year-old man came to the emergency department referring weakness and the presence of a scrotal mass. At physical examination, a voluminous mass was found, with necrotic phenomena within the scrotum. Abdomen was tense and sore. Abdominal CT scan revealed a bulky testicular mass spreading to the retroperitoneal space through the inguinal canal with node enlargement. Patient underwent orchiectomy with excision of infiltrated scrotum skin. Histologic diagnosis confirmed a typical form seminoma. The patient was then treated with a cisplatin-based chemotherapy, with a partial response. The patient recently relapsed and he is being treated with a new line of chemotherapy and subsequent surgery with or without radiotherapy. Conclusions: We described a rare presentation of testicular cancer. This case highlights the importance of a multidisciplinary approach to rare testis tumour presentation and early diagnosis for testicular cancers.
\end{abstract}

KEY WORDS: Testicular cancer; Large seminoma; Retroperitoneal space; Inguinal lymph nodes.

Submitted 2 June 2020; Accepted 6 July 2020

\section{INTRODUCTION}

Testicular tumours (TTs) represent about 5\% of all urological malignancies and $1-1.5 \%$ of all male neoplasms (1). The incidence of testicular cancers is 3-6 new cases per 100.000 males in Western countries, with an increase observed in the past 30 years (2), probably as a consequence of pollution. These rare tumours are more frequent between 18 and 35 years and in Scandinavian countries $(1,3)$.

Risk factors include the presence of a tumour in the contralateral testicle, Germ Cell Neoplasia in Situ (GCNIS), Klinefelter's syndrome, cryptorchidism or undescended testicle, family history of testicular cancer (2).
World Health Organization (WHO) classification distinguishes testicular neoplasms into germ cell-derived (95\%) and non-germ cell neoplasms (2). The most frequent germ-cell tumours (GCTs) are seminoma (40-50\% of cases). In about $80 \%$ of the cases, seminoma presents in a typical form (4).

TTs are often localized (68\%) and confined to the testis. Locally advanced tumours usually remain confined to the scrotum. Although rare, extension of the primary tumour to the inguinal canal can be observed, mostly among non-germ cell TTs (NGCTTs) (5). To the best of our knowledge, no previous case of large seminoma spreading in the retroperitoneum through inguinal canal has been described. In this study we report the first case of testicular cancer presenting as a voluminous ulcerated testicular mass.

\section{Case report}

A 44-year-old man self-referred to the emergency room of our hospital because of a voluminous scrotal mass associated to abdominal and pelvic pain. The patient had no fever, poor nutritional conditions and pale skin. Clinical history included smoke and thyroid goitre. Physical examination showed a voluminous scrotal mass likely with colliquative necrotic phenomena and abdominal extension (Figure 1A). The abdomen was tense and slightly painful on deep palpation.

Laboratory tests showed an anaemia with reduction in red blood cell (RBC) count $\left(3.1 \times 10^{6} \mathrm{~mm}^{3}\right.$; normal range 4.5$5.3 \times 10^{6} \mathrm{~mm}^{3}$ ), haemoglobin $(\mathrm{Hgb})$ of $6.9 \mathrm{~g} / \mathrm{dl}$ (normal range $13-16 \mathrm{~g} / \mathrm{dl}$ ), Hct of $24 \%$ (normal value $37-49 \%$ ). Tumour markers were elevated, in particular $\beta$-HGC was $4873 \mathrm{mIU} / \mathrm{ml}$ (normal range between 0-5 mUI/ml), $\alpha$-fetoprotein was $33.4 \mathrm{ng} / \mathrm{ml}$ (normal values less than $6 \mathrm{ng} / \mathrm{ml}$ were evaluated) and LDH was $9047 \mathrm{U} / \mathrm{L}$ (normal range 313-618 U/L). Complete blood tests are shown in the Table 1.

The patient underwent an abdominal CT scan, showing a voluminous scrotal sac $(28 \times 13 \times 12 \mathrm{~cm})$ with solid tissue sized $16 \times 16 \mathrm{~cm}$, occupying the scrotum with extension to the left inguinal canal and to the retroperi- 
Figure 1.

(A) Voluminous and necrotic scrotum at the diagnosis. (B) Intra-operative photograph. (C) Post-operative photograph of resected scrotal mass.

(D-F) Computed tomography shows extensive abdominal diffusion of tumour.

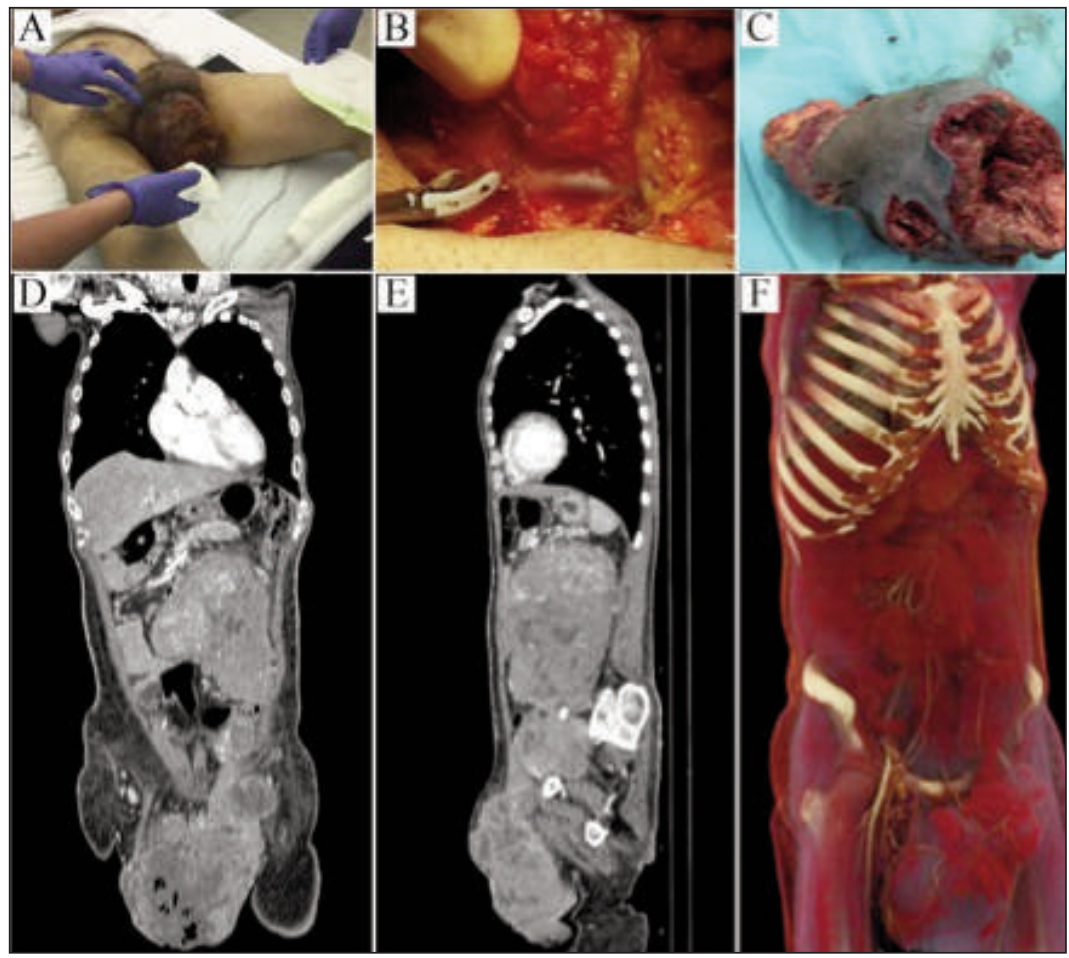

toneal space. Moreover, there was a pathological involvement of the left inguinal $(11 \times 7 \mathrm{~cm})$ and iliac-obturator $(10 \times 6 \mathrm{~cm})$ lymph nodes infiltrating the external iliac vein.

In addition, pathologic retroperitoneal lymphatic tissue was documented along the abdominal aorta for a longitudinal extension of about $20 \mathrm{~cm}$, resulting in compression of the inferior vena cava and infiltration of the external iliac vein, left renal vein and left ureter with signs of post-renal obstructive uropathy. No distant lesions to parenchymal organs were detected (Figure 1D-F).

In the context of reduced $\mathrm{Hgb}$, the patient underwent a transfusion and was hospitalized in the urology department. Unilateral orchiectomy with lymph node dissection was performed (Figure 1B). First, an inguinal incision was made and the enlarged nodes of left inguinal chain were identified. There was no clear distinction between metastatic lymph nodes and the testicular mass. After cautious isolation left inguinal nodes were dissected. Subsequently the inguinal portion of the tumour was also isolated and, after incision enlargement to the scrotum, was removed. Finally, scrotal portion of the mass was resected alongside with the surfacing necrotic skin (Figure 1C). The right testis and penile shaft were preserved (Figure 2).

Histological examination showed a typical seminoma. The neoplasm infiltrated the skin up to ulcerating it and involved lymph nodes (pT4, pN3, pM1, S3). The presence of an intra-tumour phlogistic infiltrate was also revealed. Molecular morphology investigations with immunohistochemical characterization of the tumour showed positivity for Octamer-binding transcription factor (OCT) 3/4, Placental alkaline phosphatase (PLAP), $\beta$-HGC, CD117, Leukocyte common antigen (LCA, in the intra tumour inflammatory component) and CD30.

Following surgery, the patient received four three-weekly cycles of standard BEP (Bleomycin 30 UI IV weekly on days 1.8 and 15; Etoposide $100 \mathrm{mg} / \mathrm{m}^{2} \mathrm{IV}$ on days 1-5; Cisplatin $20 \mathrm{mg} / \mathrm{m}^{2}$ IV on days 1-5 (6).

CT scan taken one month after the completion of chemotherapy showed a great deal of reduction in the retroperitoneal lymph node masses $(6 \times 4 \mathrm{~cm}$ current vs $17 \times 12 \mathrm{~cm}$ prior). Serum level of tumour markers was also decreased (Table 2).

Subsequently, the patient underwent CT-scan at 3-month intervals. Abdominal and chest imaging showed a stable disease (SD) according to the Response Evaluation Criteria in Solid Tumors (RECIST) (7) with no parenchymal metastases for one year and half. A progressive disease (PD) was documented after 18 months. CT-scan showed a new dimensional increase in the left periaortic lymph node tissue ( $55 \times 35 \mathrm{~mm}$ current vs $50 \times 25 \mathrm{~mm}$ prior), along the left external iliac chains ( $57 \times 44 \mathrm{~cm}$ current vs $47 \times 37 \mathrm{~cm}$ prior) and the appearance of infiltration of the left iliac and 
Figure 2.

(A) Post-operative photograph. An inguinal and scrotal incision was made and the voluminous necrotic scrotal mass was removed. (B) Photograph of inguino-scrotal region on follow-up at 12 months.

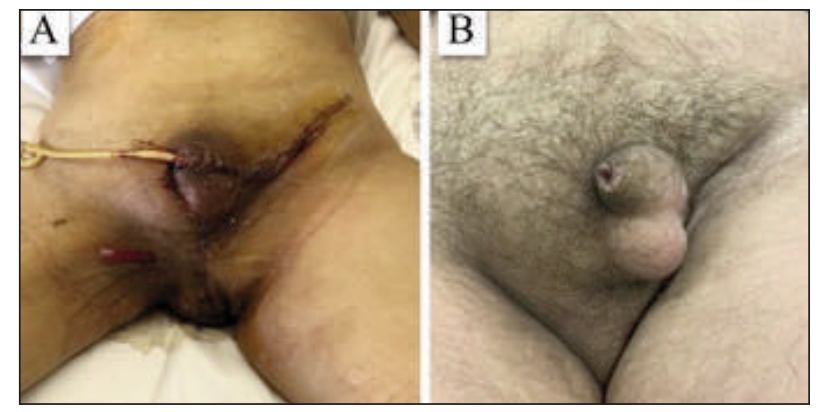

Table 2.

Tumour markers in the eighteen months following chemotherapy.

\begin{tabular}{|l|c|c|c|c|}
\hline & November 2018 & March 2019 & June 2019 & April 2020 \\
\hline Alpha-fetoprotein (ng/ml) & 9 & 3.20 & 1.60 & 60.79 \\
Beta-HCG (mUl/ml) & $<1$ & $<1$ & $<1$ & $<1$ \\
LDH (U/L) & 422 & 179 & 216 & 2580 \\
\hline
\end{tabular}

psoas muscles by the pathological lymph node tissue (7). Moreover, the patient underwent a PET-CT scan that showed an intense metabolic activity corresponding to a voluminous lymph node masses $(10 \times 13 \mathrm{~cm})$ in the left iliac region, infiltrating the left ileo-psoas muscle.

After considering the disease progression, we had a multi-disciplinary meeting. As salvage chemotherapy the patient is being treated with four three-weekly cycles of standard TIP (Paclitaxel $175 \mathrm{mg} / \mathrm{m}^{2}$ IV on day 1; Cisplatin $20 \mathrm{mg} / \mathrm{m}^{2}$ IV on days 1-5; Ifosfamide $1000 \mathrm{mg} / \mathrm{m}^{2}$ IV on days 1-5). In case of mass reduction, a combined surgical retroperitoneal lymph node dissection (RPLND) and radiotherapeutic approach will be evaluated.

\section{Discussion}

In this report, we described a rare case of large seminoma extending to the inguinal canal with diffuse retroperitoneal spreading and skin ulceration. Presentation at advanced stage or even metastatic at diagnosis is more common for NGCTTs (5).

Our case is paradigmatic for several reasons. First of all, the age of diagnosis. Our patient presented a primary testicular cancer in the absence of risk factors and at an age older than usual. This highlights the importance of genital examination at every age, even when the probability of a testicular tumour is low. Moreover, our patient had a very unusual presentation. Indeed, while most of testis cancers are diagnosed as localized tumours of few centimeters in diameter, in our case the patient turned to physicians only when symptomatic. When investigating the reasons why the patient delayed the primary intervention, a complex mix of personal, familiar and social causes emerged. Several studies have shown a detrimental effect of low socio-economic and familiar status on cancer awareness and intervention timing $(8,9)$. In a recent analysis Macload et al. showed that socio-economic status was associated with poorer oncological outcomes and a more difficult access to primary treatment in patients with testicular cancer (10). Our case corroborates these evidences and suggests the importance of a social tissue that could led to prompt access to primary care and early diagnosis. It is of note that the Italian one is a single payer healthcare system. In consequence, cure costs are not one of the major barriers to early diagnosis and treatment. However, even in this context weaker social strata still exist. Within this strata population could be more susceptible to experiment worse oncological outcomes. In fact, even after a wide surgical excision and associated chemotherapy, as recommended by international guidelines (11), we obtained only a partial response with a subsequent relapse of the disease.

Furthermore, in our case is evident how, even if cisplatin-based regimen is effective on testis cancer, a multidisciplinary approach should be warranted.

Early diagnosis, a multidisciplinary approach and a close follow-up remain mandatory to improve prognosis of testicular cancer $(12,13)$.

After relapse, our patient will undergo four cycles of TIP (14). Surgery and radiotherapy should be considered in the case of mass reduction and resectable masses with small residual tumour (15). Moreover, a close follow-up of all psychological aspects was planned in consideration of the high psychological burden of testis cancer.

\section{Conclusions}

In conclusion, we reported an extremely rare presentation of locally advanced testis cancer, resulting from the combination of cancer and patient related conditions. Early diagnosis is fundamental to guarantee a good oncological prognosis for testis cancer. Moreover, a multidisciplinary approach is important to guarantee a good oncological outcome.

\section{REFERENCES}

1. Chia VM, Quraishi SM, Devesa SS, et al. International trends in the incidence of testicular cancer, 1973-2002. Cancer Epidemiol Biomark Prev. 2010; 19:1151-9.

2. Huyghe E, Matsuda T, Thonneau P. Increasing incidence of testicular cancer worldwide: a review. J Urol. 2003; 170:5-11.

3. Shanmugalingam T, Soultati A, Chowdhury S, et al. Global incidence and outcome of testicular cancer. Clin Epidemiol. 2013; 5:417-27.

4. Moch H, Cubilla AL, Humphrey PA, et al. The 2016 WHO classification of tumours of the urinary system and male genital organsPart A: Renal, penile, and testicular tumours. Eur Urol. 2016; 70:93-105.

5. Palumbo C, Mistretta FA, Mazzone E, et al. Contemporary incidence and mortality rates in patients with testicular germ cell tumors. Clin Genitourin Cancer. 2019; 17:e1026-35.

6. Saxman SB, Finch D, Gonin R, Einhorn LH. Long-term follow-up of a phase III study of three versus four cycles of bleomycin, etoposide, and cisplatin in favorable-prognosis germ-cell tumors: the Indian University experience. J Clin Oncol. 1998; 16:702-6. 
7. Eisenhauer EA, Therasse P, Bogaerts J, et al. New response evaluation criteria in solid tumours: revised RECIST guideline (version 1.1). Eur J Cancer 1990. 2009; 45:228-47.

8. Mihor A, Tomsic S, Zagar T, et al. Socioeconomic Inequalities in Cancer Incidence in Europe: A Comprehensive Review of Populationbased Epidemiological Studies. Radiol Oncol. 2020; 54:1-13.

9. Marchioni M, Martel T, Bandini M, et al. Marital status and gender affect stage, tumor grade, treatment type and cancer specific mortality in T1-2 NO MO renal cell carcinoma. World J Urol. 2017; 35:1899-905.

10. Macleod LC, Cannon SS, Ko O, Schade GR, et al. Disparities in Access and Regionalization of Care in Testicular Cancer. Clin Genitourin Cancer. 2018; 16:e785-93.

11. Honecker F, Aparicio J, Berney D, et al. ESMO Consensus
Conference on testicular germ cell cancer: diagnosis, treatment and follow-up. Ann Oncol. 2018; 29:1658-86.

12. Warde P, Specht L, Horwich A, et al. Prognostic factors for relapse in stage I seminoma managed by surveillance: a pooled analysis. J Clin Oncol 2002;20:4448-52.

13. Aparicio J, Germà JR, García del Muro X, et al. Risk-adapted management for patients with clinical stage I seminoma: the Second Spanish Germ Cell Cancer Cooperative Group study. J Clin Oncol. 2005; 23:8717-23.

14. Park S, Lee S, Lee J, et al. Salvage chemotherapy with paclitaxel, ifosfamide, and cisplatin (TIP) in relapsed or cisplatin-refractory germ cell tumors. Onkologie. 2011; 34:416-20.

15. Oldenburg J, Fosså SD, Nuver J, et al. Testicular seminoma and non-seminoma: ESMO Clinical Practice Guidelines for diagnosis, treatment and follow-up. Ann Oncol Off J Eur Soc Med Oncol. 2013; 24 Suppl 6:vi125-132.

\section{Correspondence}

Alessio Antonaci, MD

Luigi Schips, MD

Michele Marchioni, MD

Daniela Fasanella, MD (Corresponding Author)

danielafasanella@libero.it

Department of Medical, Oral and Biotechnological Sciences, G. d'Annunzio University of Chieti, Urology Unit, SS Annunziata Hospital

Via dei Vestini, 66100, Chieti (Italy)

Vikiela Galica, MD

Department of Biotechnological and Applied Clinical Sciences,

University of L'Aquila "San Salvatore" Hospital, L'Aquila (Italy)

Nicola Tinari, $M D$

Department of Medical, Oral and Biotechnological Sciences and Center for Advance Studies and Technology (CAST), G. D'Annunzio University of Chieti, Chieti (Italy)

Jamara Giampietro, $M D$

Pietro Di Marino, MD

Clinical Oncology Unit, SS Annunziata Hospital, Chieti (Italy)

Andrea Delli Pizzi, MD

Raffaella Basilico, MD

Department of Neuroscience, Imaging and Clinical Sciences, G. D'Annunzio University of Chieti, Chieti (Italy) 